\title{
Cancer stem cells and their detection using specific cancer stem cell markers- a new strategy for cancer therapies
}

\author{
Khalida I. Noel $1{ }^{*}$, Rana M. Raoof ${ }^{2}$ and Nibras H. Khamees 1 \\ ${ }^{1}$ Human Anatomy Department, College of Medicine, Mustansiriyah University, Baghdad, Iraq. \\ ${ }^{2}$ Anatomy Department, College of Medicine, University of Mosul, Mousl, Iraq.
}

GSC Biological and Pharmaceutical Sciences, 2021, 17(03), 094-099

Publication history: Received on 11 November 2021; revised on 13 December 2021; accepted on 15 December 2021

Article DOI: https://doi.org/10.30574/gscbps.2021.17.3.0357

\begin{abstract}
Background: In the previous theories of cancer, they considered that cancer was a homogeneous which mean that the tumor had only tumor cells and for this reason the treatment for any tumor directed to kill these tumor cells. But, with rising of the metastatic cases of cancer patients, another theory have been raised, that the cancer is a heterogeneous disease which composed of tumor cells that previously the chemotherapy and other cancer therapies directed toward them, in addition there is another group of cells, called cancer stem cells (CSCs), these are more aggressive than the tumor cells that can force the poor microenvironment of the cancer tissue and survive and also they are undifferentiated cells so can undergo mitosis to produce more tumor cells and another group of cancer stem cells in contrast to the tumor cells, which considered a post mitotic and not divided.
\end{abstract}

Objective: Demonstrate some of cancer stem cell markers that considered an important indicators of early cancer development and lately to detect cases of metastasis.

Conclusion: The theory of the presence of cancer stem cells is more acceptable and applicable and so the cancer therapy must be directed to these groups of cancer stem cells.

Keywords: SOX2; ALDH1; EZH2; Cancer stem cell; OCT4; NANOG

\section{Introduction}

\subsection{Stem cells}

Undifferentiated cells that have the ability to split into undifferentiated and differentiated (specialized) cells are referred to as stem cells. These cells represent an unlimited source from which arise the different types of cells that form the tissues and organs of body. Stem cells have got large attention in the recent years as a possible therapeutic and curative tool that can help in the treatment of number of important diseases that affect large number of populations such as hear diseases, neurological disorders, diabetes and even cancer. This role of stem cells can be achieved through their ability to replace injured or defective cells. [1].

A better understanding of cancer biology could be achieved from research in the field of stem cells biology due to the resemblances between tumorigenic cells and normal stem cells [2].

\footnotetext{
* Corresponding author: Khalida I. Noel

Lecturer At Human Anatomy Department, College Of Medicine, Mustansiriyah University, Baghdad, Iraq. 


\subsection{Types}

Stem cells can be categorized into different types depending on the following criteria:

\subsubsection{According to the source of the cells:}

- $\quad$ Embryonic stem cells: they are pluripotent cells that are found in blastocyst stage in 4-5 days old human embryo and can differentiate into any cell or tissue type [3].

- $\quad$ Adult stem cells: they are multipotent cells which are present in different types of adult tissues with restricted differentiation capacity. Their main function is to heal and preserve tissues in which they are institute as in hemopoietic tissue and peripheral blood [4].

\subsubsection{According to the Differentiation potential of the cells:}

- Totipotent stem cells: this refers to the cells of the morula (4 cells stage) that can differentiate into all embryonic tissues in addition to the supporting structures such as the placenta.

- $\quad$ Pluripotent stem cells: such as the embryonic stem cells which can produce any cell or tissue type.

- Multipotent stem cells: are seen in the adult tissue with features of repair, self- renewal and differentiation [5].

\subsection{Stemness theory}

The term "stemness" refer to the process of cell differentiation and apoptosis that take place in a dynamic manner with resultant functional variability within stem cells population that correlate with high adaptation to the environmental surroundings. Another important term is "plasticity" which refers to the stem cell' ability to shift between numerous functional situations in correlation with its dynamic nature. Such dynamic functional situations include asymmetrical / symmetrical cell division, proliferation, quiescence, and epithelial transmission [6].

\subsection{Normal to cancer stem cells' trail}

The following subsequent events could play part in development of cancer to a minimum degree:

- DNA mutations and epigenetic mechanism alteration that leads to modification of the cell cycle control, signaling pathway and cellular metabolism [7].

- Diverse alterations in stem cells microenvironment that affects the resident stem cells niche inside different body tissues. [8].

\subsection{Cancer stem cells (CSCs)}

Cancer cells that have the capacity of self-renewing and abnormal division are referred to as cancer stem cells (CSCs). These cells are proposed to facilitate neoplastic development, tumor metastasis, and relapse after treatment [9].

Cancer stem cells might be a separate entity or a subset of tumor progenitor cells, tumor-initiating cells, disseminated tumor cells (DTCs), or circulating tumor cells (CTCs) [10]. CSCs were initially speculated trying to clarify both intermittent and metastatic growth development and cancer heterogeneity. Following this speculation, just one or few CSCs are expected to reiterate the cancer and its underlying heterogeneity. What's more, numerous investigations have exhibited that most chemotherapeutics and radiation face resistance from these CSCs and subsequently CSCs could tolerate initial therapy. This survival capacity implies that recurrence and cancer progression after treatment could be caused by the presence of these CSCs. In addition, a lot of benefits could be achieved by focusing future research on these CSCs that ultimately might results in further improvement in cancer treatment and expanding the cure rate in patients with cancer [11].

\subsection{Cancer stem cells' properties}

- Differentiation: represent the ability to heterogeneously inherit cells and generalize to all unique types of cancer cells

- $\quad$ Self-renewal: represent the facility to transfer new undifferentiated stem cells, have the capacity to proliferate, expand and differentiate and accordingly preserve the pool of stem cells.

- Control of homeostasis and stability of differentiation [12]. 


\subsection{Cancer stem cell markers}

An assortment of markers is hypothesized to recognize CSCs. In any case, the clinical meaning of these markers remains generally problematic, partially, the heterogeneity of numerous tumors results in the presence of big number of anticipated markers for CSCs [13]. A larger part of the anticipated CSC markers are types of cell surface proteins that are recognized by enzymatic assays and immunohistochemistry. This has the additional advantage of having the option to isolate out and enhance the CSC populace; in any case, various proteins inside the cells have the protentional to act as CSC markers, hypothetically, that might be utilized to distinguish them in patients [14], a portion of these include:

\subsection{Enhancer of Zeste Homolog 2 (EZH2)}

It is a histone lysine methyl transferase having a place within the family of polycomb group proteins. It has been found that in patients with hematological and solid tumors, there is an overexpression of EZH2 [15].

Polycomb group (PcG) proteins in warm blooded creatures assume significant parts in cell development and separation by directing downstream genes' expression. They comprise two core complexes, namely "polycomb repressive complex 1 (PRC1)" and polycomb repressive complex 2 (PRC2)" [16].

It has been estimated that EZH2 contribute to the growth and progression of cancers. This assumption is based on the correlation between poor prognosis in various malignancies and the high levels of EZH2. Different types of microRNAs (miRNAs) can down regulate EZH2 expression by silencing a number of post-transcriptional genes, as has been demonstrated by various studies [17].

Because of EZH2' potential role in malignant tumors growth and progression, it has been well-thought-out as an important therapeutic target for cancers. Collected investigations demonstrated that hindrance of EZH2 via gene knockdown or the use of small molecular inhibitors, can lead to reduction in malignancy cell development and formation of tumors [18].

Collected evidence also showed that EZH2 also played a critical role in progression and metastasis of several cancers [19], EZH2 could promote tumor angiogenesis through VEGF stimulation in a paracrine circuit manner [20]. EZH2 is biologically functioned as a transcriptional repressor that silences more than 200 tumor suppressor genes, its oncogenic properties made EZH2 a promising risk indicator and target for cancer therapy [21].

\subsection{Aldehyde dehydrogenase A1 (ALDH1)}

Aldehyde dehydrogenase action was utilized to isolate great number of stem cells in neoplasia and normal cells. Aldehyde dehydrogenases (ALDH) are a family of ubiquitous enzymes that control the conversion of aldehydes to their corresponding carboxylic acids by irreversible oxidative reaction. ALDH has several isoforms (about 17), and of them, aldehyde dehydrogenases 1 (ALDH1) displays a high level of activity in neural and hematopoietic stem cells. This action take place in early stages of stem cells differentiation via the oxidation of retinol to retinoic acid [22].

Developing proof recommends that in different cancer types, such as cancers of the brain, breast, prostate and lung, human multiple myeloma and acute myeloid leukemia, there is an overexpression of ALDH1 [23]. Accordingly, ALDH1 activity could be used for the monitoring of both normal and malignant stem cell populaces, in the form of a typical tumor marker [24]. Lately, many investigations have revealed the presence of positive correlation between ALDH1 expression and poor clinical prognosis in different types of cancers, such as that of stomach, lung and pancreas [25].

ALDH1 gives protection from oxidative harm and alkylating chemotherapeutic agents through its catalytic action over the irreversible oxidization of cell aldehydes. ALDH action was likewise exceptionally helpful for isolation of tumorigenic cells in some human colorectal xenografts [26].

\subsection{SOX genes (SOX2)}

SOX genes encode transcription factors that identified depending on a conserved keynote contained by the High Mobility Group (HMG) domain, though, SOX genes belong to the HMG superfamily [27], It has been shown that the SOX genes can manage various developmental processes, including hair follicle, gut, lens, B-cell, blood vessel, and muscle development [28]. Their potential effects have likewise been found in different neoplastic tissues which depend on tumor status and types and thus may work as tumor suppressors or promoters.

It is well known that certain embryonic stem cells genes are involved in the process of tumorigenesis and SOX2 is a fundamental player in this regard. Apart from cell clusters residing within lymph node, SOX2 was reliably down- 
regulated in some cancer types. On this basis, overexpression of SOX2 mRNA in the primary tumor is suggestively linked to lymph node metastasis [29].

\subsection{Octamer-binding transcription factor 4 (OCT4)}

OCT4 is a transcription factor of the POU family, also identified as POU5f1, encoded by POU5F1 gene on chromosome 6 that plays a crucial role (gatekeeper) in self-renewal and preservation of pluripotency in embryonic stem cells, also in somatic cell reprogramming and it has been used as a promising CSC marker [30,31].

The presence of OCT4 macromolecule is related to poor prognosis in internal organ cancer, non-small-cell cancer and muscle system epithelial cell cancer [32,33]. A potential mechanism that could be responsible for the additional aggressive behavior of cancer and poorer clinical outcomes with OCT4-expressing cells is the presence of somatic cell constitution in cancer associated with OCT4-mediated adjustment and associated chemoresistance [34].

\subsection{Homeobox protein (NANOG)}

NANOG is a transcription factor that helps embryonic stem cells maintain pluripotency by suppressing cellular determinants [35]. Numerous types of carcinomas are associated with NANOG.

In 2003, a multipotent marker for NANOG stem cells was recognized [36]. It has a specific expression in pluripotent human embryonic stem cells at implantation, primordial germ cells, embryonic carcinoma cells, in vitro cultured embryonic stem cells, and embryonic germ cells. It also plays a role in cell proliferation promotion.

The expression of NANOG is absent in endodermal sinus tumors, immature teratoma and chorionic carcinoma. On the other hand, NANOG is over-expressed in embryonic carcinoma and dysgerminoma [37]. It can be used to differentiate between germ cell tumors and non-germ cell tumors [38]. NANOG is also considered as one of the specific and sensitive markers for the identification of metastatic germ cell cancer [39]. Therefore, due to the importance of maintaining selfrenewal and multipotential capacity in various malignancies, NANOG is a growing focus in cancer biology and progression.

Previous researches had established that overexpression of certain transcription factors namely, SOX2, NANOG and OCT4, individually or combined, is an important cause of tumor metastasis, tumorigenicity and even distant tumor recurrence following chemoradiation in many malignancies [40,41].

\section{Conclusion}

The use of cancer stem cell markers have a beneficial role in cancer detection, cancer progression and metastases which then give an important modulation of cancer treatment strategies helping in suppression of tumor recurrence.

\section{Compliance with ethical standards}

\section{Acknowledgments}

This work is not supported by a research grant.

\section{Disclosure of conflict of interest}

The authors declare that they have no conflict of interest in connection with the publication of this manuscript.

\section{References}

[1] Till JE, Stem cells in differentiation and neoplasia. J Cell Physiol Suppl. 1982; 1: 3-11.

[2] Boiani M, Scholer HR. Regulatory networks in embryo-derived pluripotent stem cells. Nat Rev Mol Cell Biol. 2005; 6: 872-884.

[3] Potten ChS et al. Epithelial stem cells, the mucosal governor. Int j Exp Path. 1997; 78: $219-243$.

[4] Santagata S, Ligon KL and Hornick JL, Embryonic stem cell transcription factor signatures in the diagnosis of primary and metastatic germ cell tumors. Am J Surg Pathol. 2007; 31: 836-845. 
[5] Kumar S, Singh NP. Review article Stem cells: A new paradigm. Indian J of Human Genetic. 2006; 12: 4-10.

[6] Zeuner A, Todaro M, De Maria R. Colorectal Cancer Stem Cells from the Crypt to the Clinic. Cell Stem Cell. 2014; 15(6): 692-705.

[7] Booth C, Potten CS. Gut instincts: Thoughts on intestinal epithelial stem cells. J Clin Invest. 2000; 105: 1493-1499.

[8] Marshman E, Booth C, Potten CS. The intestinal epithelial stem cell. Bio essays. 2002; 24: 91-98.

[9] Kreso A, Dick JE. Evolution of the cancer stem cell model. Cell Stem Cell. 2014; 14(3): 275-291.

[10] Lathia JD. Cancer stem cells: moving past the controversy. CNS Oncology. 2013; 2(6): 465-467.

[11] Kyjacova L, Hubackova S, Krejcikova K, Strauss R, Hanzlikova H, Dzijak R, et al., Radiotherapy-induced plasticity of prostate cancer mobilizes stem-like non-adherent, Erk signaling-dependent cells. Cell death and differentiation. 2015 Jun; 22(6): 898.

[12] Garza -Trevino et al., Understanding the colon cancer stem cells and perspective on treatment. Cancer cell International. 2015; 15: 2.

[13] Deng Q, Tang DG. Androgen receptor and prostate cancer stem cells biological mechanisms and clinical implications. Endocrine-Related Cancer. 2015; 22(6): T209-T220.

[14] Pattabiraman D, Weinberg R, Tackling the cancer stem cells - what challenges do they pose Nature Reviews. Drug Discovery. 2014; 13(7): 497-512.

[15] Borbone E, Troncone G, Ferraro A, Jasencakova Z, Stojic L, Esposito F, et al., Enhancer of zeste homolog 2 overexpression has a role in the development of anaplastic thyroid carcinomas. The Journal of Clinical Endocrinology \& Metabolism. 1Apr 2011; 96(4): 1029-38.

[16] Li L. EZH2: Novel therapeutic target for human cancer. Biomedicine. 2014; 4: 1.

[17] Yan KS, Lin CY, Liao TW, Peng CM, Lee SC, Liu YJ, et al. EZH2 in cancer progression and potential application in cancer therapy: A friend or foe?. International journal of molecular sciences. 31 May 2017; 18(6): 1172.

[18] Yang YA, Yu J. EZH2, an epigenetic driver of prostate cancer. Protein Cell. 2013; 4: 331-41.

[19] Varambally S, Dhanasekaran SM, Zhou M, Barrette TR, Kumar-Sinha C, Sanda MG, et al., The polycomb group protein EZH2 is involved in progression of prostate cancer. Nature. Oct 2002; 419(6907): 624.

[20] Lu C, Han HD, Mangala LS, Ali-Fehmi R, Newton CS, Ozbun L, et al. Regulation of tumor angiogenesis by EZH2. Cancer Cell. 2010; 18: 185-197.

[21] Kim KH, Roberts CW. Targeting EZH2 in cancer. Nature Medicine. 2016; 22: 128-134.

[22] Ibarra I, Erlich Y, Muthuswamy SK, Sachidanandam R, Hannon GJ, A role for microRNAs in maintenance of mouse mammary epithelial progenitor cells. Genes \& development. 15 Dec 2007; 21(24): 3238-43.

[23] Jiang F, Qiu Q, Khanna A, Todd NW, Deepak J, Xing L, et al. Aldehyde dehydrogenase 1 is a tumor stem cellassociated marker in lung cancer. Molecular cancer research. 1 Mar 2009; 7(3): 330-8.

[24] Moreb JS, Mohuczy D, Ostmark B, Zucali JR, RNAi-mediated knockdown of aldehyde dehydrogenase class-1A1 and class-3A1 is specific and reveals that each contributes equally to the resistance against 4 hydroperoxycyclophosphamide. Cancer Chemother Pharmacol. 2007; 59: 127-36.

[25] Ni C, Zhang Z, Zhu X, Liu Y, Qu D, Wu P, et al. Prognostic value of CD166 expression in cancers of the digestive system: a systematic review and meta-analysis. PloS one. 5 Aug 2013; 8(8): e70958.

[26] Hessman CJ, Bubbers EJ, Billingsley KG, Herzig DO, Wong MH. Loss of expression of the cancer stem cell marker aldehyde dehydrogenase 1 correlates with advanced-stage colorectal cancer. The American Journal of Surgery. 1 May 2012; 203(5): 649-53.

[27] Titulaer MJ, Klooster R, Potman M, Sabater L, Graus F, Hegeman IM, et al. SOX antibodies in small-cell lung cancer and Lambert-Eaton myasthenic syndrome: frequency and relation with survival. J Clin Oncol. 2009; 27: 42604267.

[28] Endo Y, Deonauth K, Prahalad P, Hoxter B, Zhu Y, Byers SW. Role of Sox-9, ER81 and VE-cadherin in retinoic acidmediated trans-differentiation of breast cancer cells. PLoS One. 2008 Jul; 16; 3(7): e2714. 
[29] Russo MV, Esposito S, Tupone MG, Manzoli L, Airoldi I, Pompa P, et al. SOX2 boosts major tumor progression genes in prostate cancer and is a functional biomarker of lymph node metastasis. Oncotarget. 15 Mar 2016; 7(11): 12372.

[30] Niwa H, Miyazaki J, Smith AG. Quantitative expression of Oct-3/4 defines differentiation, dedifferentiation or selfrenewal of ES cells. Nat Genet. 2000; 24: 372-376.

[31] Atlasi Y, Mowla SJ, Ziaee SA, Bahrami AR. OCT-4, an embryonic stem cell marker, is highly expressed in bladder cancer. International Journal of Cancer. 1 Apr 2007; 120(7): 1598-602.

[32] Koo BS, Lee SH, Kim JM, Huang S, Kim SH, Rho YS, Bae WJ, Kang HJ, Kim YS, Moon JH, Lim YC. Oct4 is a critical regulator of stemness in head and neck squamous carcinoma cells. Oncogene; Oncogene. 2015; 34: 2317-2324.

[33] Abubaker K, Luwor RB, Zhu H, McNally O, Quinn MA, Burns CJ, Thompson EW, Findlay JK, Ahmed N. Inhibition of the JAK2/STAT3 path-way in ovarian cancer results in the loss of cancer stem cell-like characteristics and a reduced tumor burden. BMC Cancer. 2014; 14: 317.

[34] Ohnishi K, Semi K, Yamamoto T, Shimizu M, Tanaka A, Mitsunaga K, Okita K, Osafune K, Arioka Y, Maeda T, Soejima H, Moriwaki H, Ya-manaka S, Woltjen K, Yamada Y. Premature termination of reprogramming in vivo leads to cancer development through altered epigene-tic regulation. Cell. 2014; 156: 663-77.

[35] Heurtier V, Owens N, Gonzalez I, et al. The molecular logic of Nanog-induced self-renewal in mouse embryonic stem cells. Nat Commun. 2019; 10: 1109.

[36] Chambers I, Colby D, Robertson M, Nichols J, Lee S, Tweedie S and Smith A. Functional expression cloning of Nanog, a pluripotency sustaining factor in embryonic stem cells. Cell. 2003; 113: 643-655.

[37] Mitsui K, Tokuzawa Y, Itoh H, Segawa K, Murakami M, Takahashi K, Maruyama M, Maeda M, Yamanaka S. The homeoprotein Nanog is required for maintenance of pluripotency in mouse epiblast and ES cells. Cell. 2003; 113: 631-642.

[38] Zhang S, Balch C, Chan MW, Lai HC, Matei D, Schilder JM, Yan PS, Huang TH, Nephew KP. Identification and characterization of ovarian cancer-initiating cells from primary human tumors. Cancer Res. 2008; 68: 4311-4320.

[39] Santagata S, Ligon KL, Hornick JL. Embryonic stem cell transcription factor signatures in the diagnosis of primary and metastatic germ cell tumors. Am J Surg Pathol. 2007; 31: 836-845.

[40] Noel KI, Ibraheem MM, Ahmed BS, Hameed AF, Khamees NH, Akkila SS. Expression of Oct4 stem cell marker in benign prostatic hyperplasia and normal tissue around the prostatic carcinoma in a sample of Iraqi patients. Egypt. J. Histol. 2020; 43: 245-254.

[41] Novak D, Hüser L, Elton JJ, Umansky V, Altevogt P, Utikal J. SOX2 in development and cancer biology. Seminars in Cancer Biology. 2020; 67(1): 74-82. 